九州大学学術情報リポジトリ

Kyushu University Institutional Repository

\title{
A Study on the Distribution of Nonylphenol in Estuaries in Busan, Korea
}

Kim, Dong-Myung

Department of Ecological Engineering, Pukyong National University

Kim, Sunyoung

Department of Ecological Engineering, Pukyong National University

Suk, Jiwon

Chung, Yong-Hyun

Department of Ecological Engineering, Pukyong National University

他

https://doi.org/10.5109/27362

出版情報: 九州大学大学院農学研究院紀要. 58 (2)，pp.313-318，2013-09. Faculty of Agriculture， Kyushu University

バージョン :

権利関係 : 


\title{
A Study on the Distribution of Nonylphenol in Estuaries in Busan, Korea
}

\author{
Dong-Myung KIM ${ }^{1}$, Sunyoung KIM ${ }^{1}$, Jiwon SUK ${ }^{1}$, Yong-Hyun CHUNG ${ }^{1}$, \\ Young-Mog KIM ${ }^{2}$, Kyong Joon $\mathbf{R O H}^{3}$, Seok Jin $\mathbf{O H}^{4}$, \\ Yuji Oshima and Ik Joon KANG ${ }^{5 *}$
}

\author{
Laboratory of Marine Environment Science, Division of Animal \& Marine Bioresource Sciences, \\ Department of Bioresource Sciences, Faculty of Agriculture, \\ Kyushu University, Fukuoka 812-8581, Japan \\ (Received April 26, 2013 and accepted May 16, 2013)
}

\begin{abstract}
Nonylphenol (NP) is known as one of Endocrine Disrupting Chemicals (EDCs) is the degradation product of Nonylphenol ethoxylates (NPEs) being used as nonionic surfactant. NP is classified as an endocrine disrupter capable of interfering with the hormonal system of numerous organisms. In order to understand the behavior of NP in urban stream, this study was examined occurrence of NP in estuary of Nakdong River and Suyoung River. Water sampling for a raining season was performed in July 2011 and about the dry season was conducted in October 2011. During the survey period, the range of NP concentration in estuary of the Nakdong River was 137.1 10,931.5 ng/L and the average was 2,315.1 ng/L. Surface water of estuary of Suyoung River had the range of $144.0 \sim 2,469.6 \mathrm{ng} / \mathrm{L}$ and the average of $712.0 \mathrm{ng} / \mathrm{L}$. It was found that NP concentration of Suyoung River and Nakdong River was similar or lower compared to results of studies in Korea and other countries.
\end{abstract}

Key words: endocrine disruptor, nonylphenol, Nakdong River, Suyeong River, GC/MS

\section{INTRODUCTION}

As more than 100,000 kinds of synthetic chemicals are produced and distributed through continuous development of the chemical industry, organic chlorine compounds such as dioxin and DDT, heavy metals such as mercury, and chemicals such as synthetic estrogen cause environmental problems. After these chemicals are discharged into the environment, they are introduced into the organism and act as Endocrine Disrupting Chemicals (EDCs or Endocrine disruptors) which interfere with normal endocrine system because they have similar chemical structures of hormones. EDCs are suspected or estimated as substances that cause reproductive disorders, malformations and various cancers through interference with the normal functioning of the endocrine system in organism. They are not easily degraded in the environment and remain over a long period of time. They are also characterized by high bio concentration and accumulation. In addition, since toxic effects of EDCs, risk to the environment and impacts on physiology of biological groups are not clearly known yet, it has been the subject of controversy (Colborn et al., 1993; Kavlock et al., 1996; KORDI, 2004).

\footnotetext{
1 Department of Ecological Engineering, Pukyong National University, Busan 608-737, Republic of Korea

2 Department of Food science and Technology, Pukyong National University, Busan 608-737, Republic of Korea

3 Department of Environmental Engineering, Pukyong National University, Busan 608-737, Republic of Korea

4 Department of Oceanography, Pukyong National University, Busan 608-737, Republic of Korea

${ }^{5}$ Open problem study program, Faculty of Agriculture, Kyushu University, Hakozaki, Fukuoka 812-8581, Korea

* Corresponding author (E-mail: kangnew@agr.kyushu-u.ac.jp)
}

Alkylphenols (APs) which is known as one of EDCs is the degradation product of Alkylphenol ethoxylates (APEs) being used as nonionic surfactant. It is the compound which combines alkyl group on benzene ring of phenol and includes Nonylphenol (NP) and Octylphenol (OP). APEs have been globally produced in about 500,000 tons per a year over the past 50 years. Among them, Nonylphenol ethoxylates (NPEs) account for 80\% of the world market. 30\% of the entire NPEs are used as the industrial and household detergents. NPEs are also used for production of emulsion polymerization, fixing agent in the chemical plant, agricultural pesticides and paints (Giger et al., 1984; Ranner, 1997). NPEs finally produce NP through a sequential degradation of ethoxylate (EO) group in aerobic and anaerobic conditions of a sewage treatment plant or water environment. As EO group gets shorter, it is known to give a big impact on aquatic organisms (Shang et al., 1999; Jonker et al., 2001). Because NP is chemically stabilized, it is detected at a significantly high concentration. It is not easily degraded in water and it is adsorbed on suspended particles to be deposited on the low ground or introduced into the sea. Through recent studies, it is reported that NP gives the effect of estrogen to fish and other aquatic organisms and it remains in the submarine sediment to be transferred to and accumulated in food chain. Therefore, NP is expected to give the additional damage due to NP's own toxicity which is potential toxicity of estrogen when exposed to trace amount and prolonged exposure (Soto et al., 1991; Jobling et al., 1996; Ferguson et al., 2000; Ferrara et al., 2001; Kang et al., 2003).

Regulations for these substances have been begun in the United States and Europe since the late 1990s. The Ministry of Environment has conducted the survey 
of contamination status and risk assessment about EDCs including NP in Korea since 1999 (MEV and NIER, 2000). However, the high levels of NP are detected in streams and estuaries of Korea due to continuous production and use of APEs. Even though most of APEs directly affect aqueous ecosystem such as river, lake or sea through sewage as surfactants and detergents, the accumulation of data about residual characteristics or concentration of APEs in stream and marine environment is lacking.

Estuary of Nakdong River provides organisms with food resources, habitats and migration pathways as the treasure of natural resource in harmony with various ecosystems. In addition, it continues to provide people with food and resources such as rich fisheries and seaweed aquaculture farming. However, due to various wastewater and waste caused by rapid development and emission from the middle and upstream regions, the environment of estuary is getting worse. Thus, conservation measures to maintain the healthy ecosystems are urgently needed.

Suyeong River is the urban stream where one third of population in Busan lives and is likely to act as a means of NP transport due to a massive influx of various wastewater from residential and industrial areas in drainage of main stream.

Therefore, the purpose of this study is to identify the contamination status and distribution characteristics of NP by measuring the residual concentration of NP in the surface waters of the estuary of Nakdong River and Suyeong River.

\section{MATERIALS AND METHODS}

\section{Study area}

Estuary of Nakdong River is the strategic point for economy and industry of Busan and the treasure of natural resources where various ecosystems exist. Since it has very diverse species and high ecological conserva- tion value, it is designated and protected by five regulations. Because the flow rate has been changed a lot and non-point pollutant source gives a strong impact, hydro geological characterization is much more complex compared to other streams in Korea. With influence of Kuroshio current, estuarine tidal variation and inflow of river, organic matter in origin of freshwater and nutrient salts in origin of seawater meet so that it has abundant fish resources. In addition, farms for various marine plants, and fishes and shellfishes are distributed. Famous seaweed farms have widely been located for a long time. However, a variety of domestic sewage, industrial wastewater and trash discharged from middle and upstream regions of Nakdong River are introduced to pollute the estuary. The estuary reclamation to build industrial complex, Newport construction, development of western industrial zone and construction of Myongji Bridge caused by designation of free economic zone give adverse effects on environment of estuary of Nakdong River (Kim, 2005; Busan Development Institute, 2005; Busan Development Institute, 2006; Choi, 2010).

Suyeong River is the local class 2 stream with stream length of $28.4 \mathrm{~km}$ and basin area of $199.57 \mathrm{~km}^{2}$. It has its source in the Wonhyo mountain in Yangsan Gun, Gyeongnam. While it moves south, it forms tributaries such as Cheolma, Seokdae and Oncheon streams. It goes through Suyeong 1 bridge and it flows into Suyeong bay. Since the upstream region in the catchment area of Hoedong is designated as water protection zone, the pollution source is less and quality of water is good. However, because the residential and industrial zones are concentrated in main stream basin, it is thought that quality of water and sediment is likely to be polluted due to the massive influx of various wastewater and the pollution may affect the entire Suyeong bay as it goes along sea current (Pack, 1997; Busan Metropolitan City, 2003).

Investigation areas of Nakdong River and Suyeong River are shown in Fig. 1. Water sampling for a raining

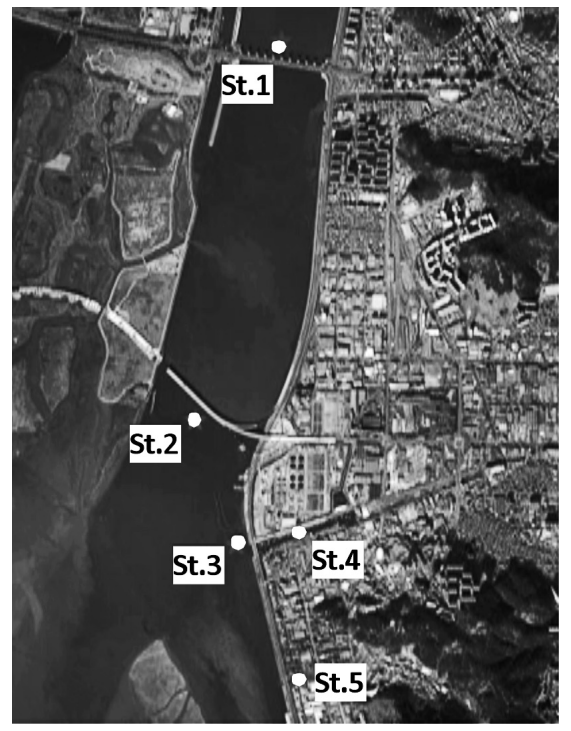

(A)

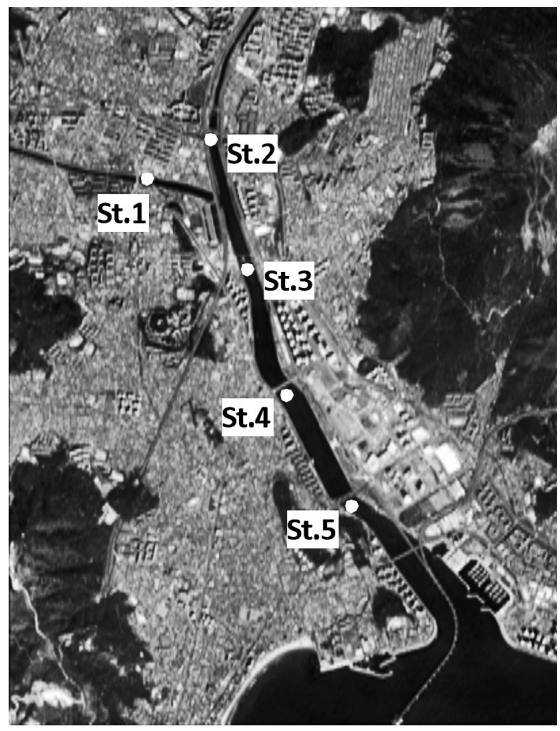

(B)

Fig. 1. Study area and sampling sites (A) Nakdong river, (B) Suyeong river. 
season was performed in July 2011. The investigation about the dry season was conducted in October 2011.

\section{Water sampling and pretreatment}

Surface water in estuary of Nakdong River and Suyeong River was taken for sampling by using a horizontal water sampler. In order to prevent the potential pollution, 2L brown hard glass bottle which was washed at least 3 times with organic solvent, methanol with pesticide grade for analysis of residual pesticide was used to transport it to the laboratory.

2L of sample was filtered using a glass fiber filter paper (GF/F $47 \mathrm{~mm}$, Whatman), and the filtered water sample was kept frozen at $-20^{\circ} \mathrm{C}$ or less. Organic solvent used for pretreatment was at pesticide grade for analysis of residual pesticide. Prior to extraction, all glass wares were washed with ultrapure water and then heated at $400^{\circ} \mathrm{C}$ or higher for more than 2 hours.

Filtered sample was passed through NEXUS (200 mg/6 mL) conditioned with Dichloromethane $10 \mathrm{~mL}$, Methanol $5 \mathrm{~mL}$ and $\mathrm{H}_{2} \mathrm{O} 5 \mathrm{~mL}$ and washed with $5 \mathrm{~mL}$ of solution mixed with $\mathrm{H}_{2} \mathrm{O}$ and Methanol in 1:1 for Solid Phase Extraction (SPE). After cartridge column was dried, it was eluted with $6 \mathrm{~mL}$ of Dichloromethane. After it was evaporated at $60^{\circ} \mathrm{C}$ with $\mathrm{N}_{2}$ gas, $2 \mathrm{~mL}$ of n-Hexane was added.

Isolute- $\mathrm{NH}_{2}(1 \mathrm{~g} / 6 \mathrm{~mL})$ used for purification was conditioned with $10 \mathrm{~mL}$ of Acetone and $10 \mathrm{~mL}$ of $\mathrm{n}-\mathrm{Hex}-$ ane. After sample was passed through it, sample was washed with $8 \mathrm{~mL}$ of a solution mixed with Dichloromethane and n-Hexane in 1:1. The sample was eluted with $8 \mathrm{~mL}$ of a solution mixed with Dichloromethane and Ethyl acetate in 1:1 and $8 \mathrm{~mL}$ of Acetone to be collected into a glass tube. These eluted solutions were evaporated with $\mathrm{N}_{2}$ gas. After they were dissolved with $100 \mu \mathrm{L}$ of Acetone and $100 \mu \mathrm{L}$ of BSTFA, 2 hours of retention time was given. Detection was performed using GC/MS (Isobe et al., 2001; Isobe and Takada, 2004).

\section{GC/ MS analysis}

For sample analysis, GC/ MS (Shimadzu, GCMS-QP2010 Plus) equipped with Capillary column, DB-5 was used. Column heating condition is following. It was maintained at $60^{\circ} \mathrm{C}$ for $2 \mathrm{~min}$ in the beginning and then $10^{\circ} \mathrm{C}$ per a minute was increased until it reached $260^{\circ} \mathrm{C}$. For sample injection, Splitless Mode (non split injection method) was used. The carrier gas was helium (He: $99.999 \%$ ) and the flow of $1.2 \mathrm{~mL} / \mathrm{min}$ was made (Table 1). The qualitative and quantitative analyses were performed by comparing retention time and peak area of each ingredient of sample with area of internal standard substance (Nonylphenol- $\mathrm{d}_{4}$ ) (Fig. 2). The weight of quantitative ion and reference ion of standard material and internal standard substance was shown in Table 2.

\section{RESULTS}

\section{Calibration curve and recovery rate}

NP standards were prepared in concentrations of 0 ,
Table 1. GC/MS analyzing conditions of NP

\begin{tabular}{|c|c|}
\hline \multicolumn{2}{|c|}{ GAS CHROMATOGRAM } \\
\hline \multicolumn{2}{|c|}{ GC-2010 Shimadzu } \\
\hline Column & DB-5 \\
\hline & $(30 \mathrm{~m} \times 0.25 \mathrm{~mm}$ i.d. $\times 0.25 \mu \mathrm{m})$ \\
\hline Inj. Temp. & $250^{\circ} \mathrm{C}$ \\
\hline Col. Temp. & $60^{\circ} \mathrm{C}(2 \mathrm{~min}) \rightarrow 10^{\circ} \mathrm{C} \rightarrow 260^{\circ} \mathrm{C}$ \\
\hline Carrier Gas & He $1.2 \mathrm{~mL} / \mathrm{min}$ \\
\hline Injection & Splitless with surge $1 \mu \mathrm{L} /$ Injection \\
\hline
\end{tabular}

\section{MASS SPECTRUaM}

QP-2010 Plus Shimadzu

Mode MS

Transfer line Temp. $\quad 260^{\circ} \mathrm{C}$

Ion Source Temp. $\quad 200^{\circ} \mathrm{C}$

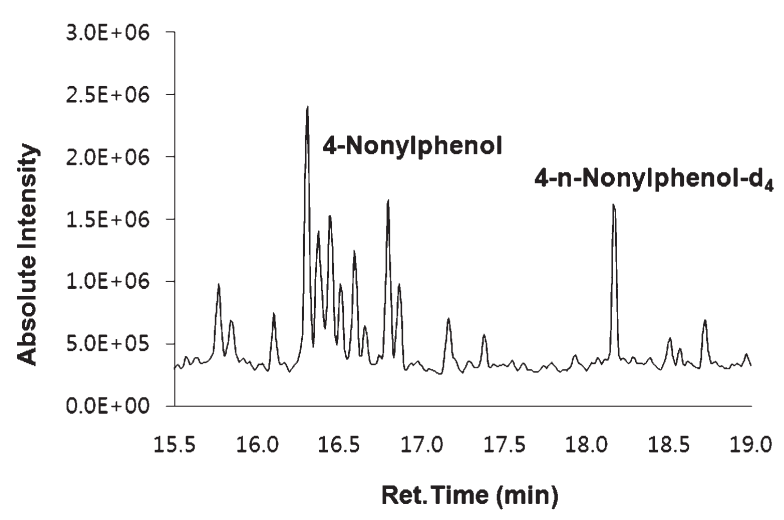

Fig. 2. Chromatogram of NP standard solution and internal standard.

Table 2. Key ions and retention time of NP and surrogate chemicals

\begin{tabular}{cccc}
\hline & Material & NP & NP-d4 \\
\hline & & 207 & \\
Key & Quantitative ion & 221 & 296 \\
ion & & 235 & \\
$(\mathrm{~m} / \mathrm{z})$ & & 163 & \\
\cline { 2 - 4 } & Reference ion & 179 & 183 \\
& & 193 & \\
\hline \multicolumn{2}{c}{ Retention time } & $16.11-16.86$ & 18.17 \\
\hline
\end{tabular}

2, 5, 10, 20, 50, 100, 200, 500 and $1000 \mathrm{ng} / \mathrm{L}$ and internal standard with concentration of $100 \mathrm{ng} / \mathrm{L}$ was additionally analyzed. Linear regression analysis was performed on calibration curve. As shown in Fig. 3, high correlation and linearity $\left(\mathrm{R}^{2}=0.9982\right)$ were shown.

In order to validate the values of NP detected in water sample of stream water, the standard materials purchased in Cica-Reagent were added into pure ionized water and were analyzed and detected according to the same method as extraction method for water sample. The recovery rate was reviewed as well. The range 


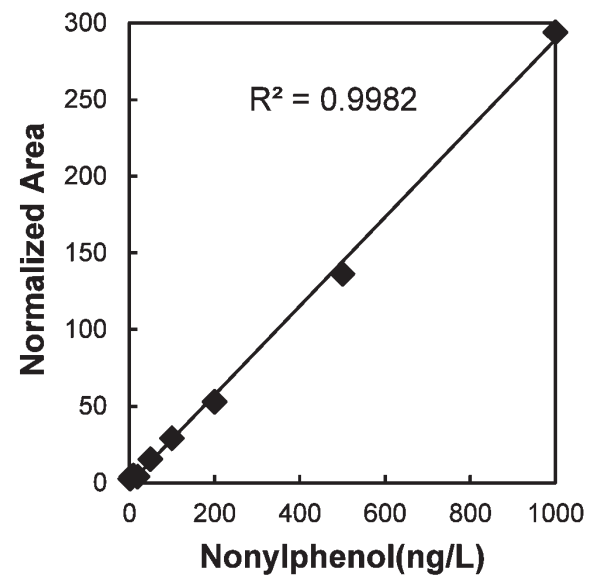

Fig. 3. Calibration curves of NP standard solution.

of recovery rate of NP according to reviewed extraction method was 92.37 118.08\%.

\section{NP distribution of estuaries of Nakdong River and Suyeong River}

In order to identify the distribution characteristics of NP compounds in estuaries of Nakdong River and Suyeong River which were study areas, results of analysis conducted from July to October 2011 was presented in Table 3.

The range of NP concentration in estuary of the Nakdong River was 137.1 10,931.5 ng/L in July 2011 and the average was $2,363.7 \mathrm{ng} / \mathrm{L}$. St.5 which was nearby industrial complex showed relatively higher concentration compared to St.1 St.4. When St.5 was excluded, the average was $221.7 \mathrm{ng} / \mathrm{L}$. The range was $141.0 \sim$ 9,189.7 ng/L in October and the average was 2,266.5 ng/L, which was lower than that in July. When St.5 point was excluded, the average was $553.7 \mathrm{ng} / \mathrm{L}$, which was relatively higher in St.1 St.4 points that those in July.

Surface water of estuary of Suyeong River had the range of 144.0 569.0 ng/L in July 2011 and the average of $303.8 \mathrm{ng} / \mathrm{L}$. The range was $324.7 \sim 2,469.6 \mathrm{ng} / \mathrm{L}$ and the average was $1,120.2 \mathrm{ng} / \mathrm{L}$ in October. The concentration of each point and average concentration were higher in October that those in July. In particular, St.1 and St.2 had relatively much higher concentrations in October than those in July.

Upon looking at average concentration of each point during the study period, the concentration of St.1 located in the upstream direction of Nakdong estuary barrage was 309.0 ng/L. On the other hand, St.2 nearby Eulsukdo bridge had the concentration of $142.1 \mathrm{ng} / \mathrm{L}$, which showed lower concentration in the downstream. St.4 and St.5 which were small streams flowing into the Nakdong River showed higher concentration distribution than that in the mainstream. In particular, St.5 which had many industrial zones and lower amount of flow had the concentration of 10,060.6 ng/L, which was approximately 40 times as much as the average concentration of mainstream. St.5 was the area where there are many metal and chemical engineering plants, precision factory and junkyard, and it had low amount of flow,

Table 3. Concentration of NP in Nakdong and Suyeong river (ng/L)

\begin{tabular}{|c|c|c|c|c|c|c|c|}
\hline & & St. 1 & St. 2 & St. 3 & St. 4 & St. 5 & Avg. \\
\hline \multirow{2}{*}{$\begin{array}{l}\text { Nakdong } \\
\text { river }\end{array}$} & 2011 July & 237.5 & 143.2 & 137.1 & 369.1 & $10,931.5$ & $\begin{array}{l}2,363.7 \\
(221.7)^{*}\end{array}$ \\
\hline & 2011 Oct. & 380.4 & 141.0 & 309.8 & $1,311.5$ & $9,189.7$ & $\begin{array}{l}2,266.5 \\
(535.7)^{*}\end{array}$ \\
\hline \multirow{2}{*}{$\begin{array}{c}\text { Suyeong } \\
\text { river }\end{array}$} & 2011 July & 569.0 & 326.9 & 319.6 & 144.0 & 159.3 & 303.8 \\
\hline & 2011 Oct. & $1,909.8$ & $2,469.6$ & 493.6 & 403.2 & 324.7 & $1,120.2$ \\
\hline
\end{tabular}

*Except St.5

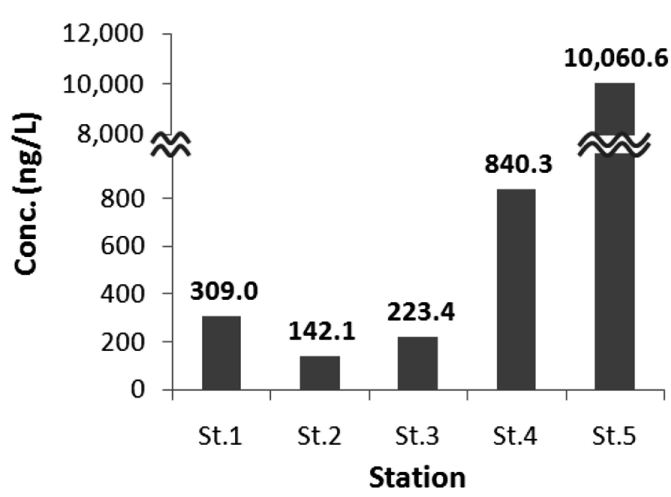

(A)

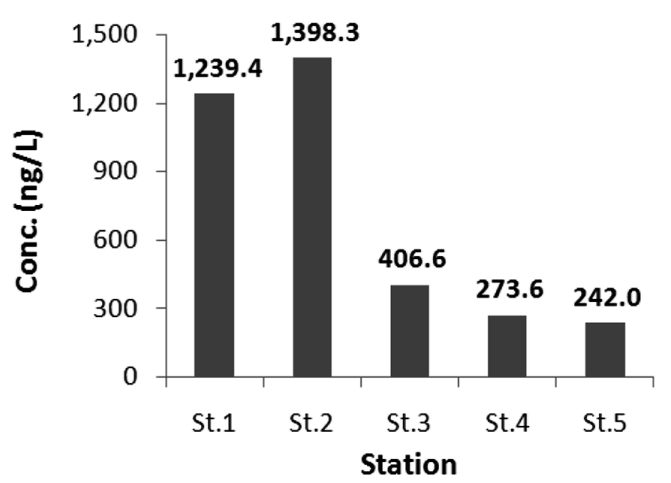

(B)

Fig. 4. Average concentration of NP in each station (A) Nakdong river, (B) Suyeong river. 
slow flow rate and low depth. In addition, it had severe odor and high turbidity.

Suyeong River showed the highest concentration in St.1 which was nearby Anrak Bridge which was the most upstream among study points and lowest concentration in St.5 in July. On the other hand, St.2 which was nearby Wondong bridge showed the highest concentration and St.5 showed the lowest distribution in October. The averages of St.2 and St. 5 were 1,398.3 ng/ $\mathrm{L}$ and $242.0 \mathrm{ng} / \mathrm{L}$, respectively. As it went from the upstream to downstream, it tended to be decreased (Fig. 4).

Upon comparing NPs in Suyeong River and Nakdong River, the average concentration of all points was higher in estuary of Nakdong River in both July and October than that in estuary of Suyeong River. However, if St.5 in estuary of Nakdong River is excluded, the estuary of Nakdong River had lower average distribution in both July and October. As it went from the upstream to downstream, the concentration tended to get lower in estuary of both Nakdong River and Suyeong River. In particular, NP concentration had high correlation $\left(\mathrm{R}^{2}=\right.$ 0.873 ) with salts in the estuary of Suyeong River in July (Fig. 5). Li et al. (2004b) reported that NP concentration had correlation with salts in estuary of Seomjin River.

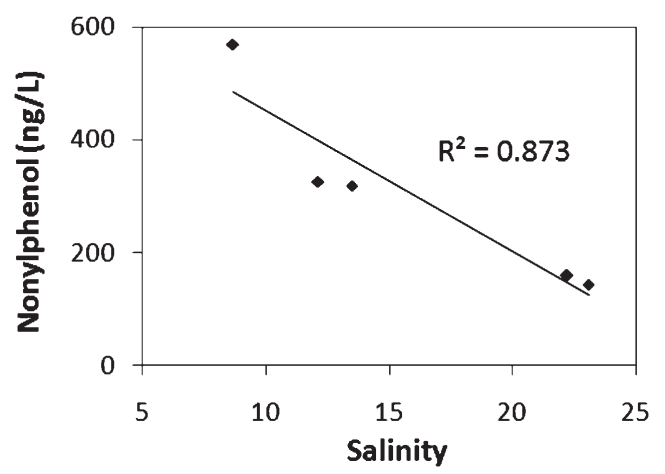

Fig. 5. Correlation of nonylphenol and salinity in Suyeong river.

\section{DISCUSSION}

The range of NP concentration of surface water of estuary of Nakdong River during the study period was $137.1 \sim 10,931.5 \mathrm{ng} / \mathrm{L}$ and average was $2,315.1 \mathrm{ng} / \mathrm{L}$. If St.5 which showed relatively high concentration compared with other points was excluded, the average was $378.7 \mathrm{ng} / \mathrm{L}$. The range in estuary of Suyeong River was $144.0 \sim 2,469.6 \mathrm{ng} / \mathrm{L}$ with an average concentration of $712.0 \mathrm{ng} / \mathrm{L}$. National Institute of Environmental Research investigated NP in 24 points of streams in Korea. The concentration of NP was ND 1,770 ng/L in 2005 (NIER, 2006) and ND 6,660 ng/L in 2006 (NIER, 2007). It implied that NP distribution of Nakdong River and Suyeong River was similar to other streams in Korea.

The range in surface water of Han River was 23.2 $187.6 \mathrm{ng} / \mathrm{L}$ (Li et al., 2004a). It was reported that branch stream in drinking water resources was ND 12,724 ng/L and Intake Station had the range of $122 \sim 2,724 \mathrm{ng} / \mathrm{L}$ (Ham et al., 2004). Like Nakdong River in this study, Han River showed higher concentration of branch stream compared to that in the mainstream. The range of NP concentration of surface water of estuary of Seomjin River flowing into Gwangyang Bay was 10.9 $63.5 \mathrm{ng} / \mathrm{L}$ with an average of $49.1 \mathrm{ng} / \mathrm{L}$, which was twice as much as the average concentration of $20.9 \mathrm{ng} / \mathrm{L}$ in inland Sea of Gwangyang Bay(Li et al., 2004b). Lee et al. (2005) reported that NP concentration in middle stream of Nakdong River was 4,330 ng/L and 1,700 ng/L in factory wastewater and domestic sewage flowing into sewage treatment facility, respectively. The concentration of over $100 \mathrm{ng} / \mathrm{L}$ was detected in entire area in nearby streams.

Upon looking at the results of studies in other countries, it was reported that NP concentration in streams flowing into Tokyo Bay and Biwa Lake in Japan was $50 \sim 1,080 \mathrm{ng} / \mathrm{L}$ (Isobe et al., 2001) and 110 3,080 ng/L (Tsuda et al., 2000), respectively. In the United States, the concentrations of urban streams in Ohio and Detroit River in Michigan were 110 500 ng/L (Rice et al., 2003) and ND 1,190 ng/L (Synder et al., 1999), respectively. It was reported that streams of German affected by effluent of sewage treatment plant and Lakes of China had concentration of $28 \sim 1,220 \mathrm{ng} / \mathrm{L}$ (Fries and Puttmann, 2003) and 1,940 32,850 ng/L (Wu et al., 2007), respectively. NP concentrations in England and Wales were ND 3,100 ng/L in seven estuaries and < 200 53,000 ng/L in five streams in 1993 and 1994, respectively (Blackburn and Waldock, 1995). On the other hands, NP concentrations were 100 2,600 ng/L and < 200 22,000 ng/L in estuary and stream, respectively in 1995 (Blackburn et al., 1999). It showed a dramatic reduction.

According to results of this study, it was found that NP concentration of Suyeong River and Nakdong River was similar or lower compared to results of studies in Korea and other countries. During study period, the average concentration of each study point was lower than $1 \mu \mathrm{g} / \mathrm{L}$ which was NP regulatory concentration in US and Europe (Renner, 1997), if a specific point was excluded. However, since NP was detected in all points and a considerably high concentration was detected at a certain point prior to investigation, it is thought that studies with wider range in vicinity and additional studies about suspended solids and sediment are needed. In addition, study on characteristics of the residual NP should be conducted on the basis of accumulation of data through continuous monitoring.

\section{ACKNOWLEDGEMENTS}

This work was supported by the research fund of the Busan Green Environment Center (11-2-30-33).

\section{REFERENCES}

Blackburn, M. A. and M. J. Waldock. 1995 Concentrations of alkylphenols in rivers and estuaries in England and Wales. Water 
Res., 29(7): 1623-9

Blackburn, M. A., S. J. Kirby and M. J. Waldock. 1999 Concentrations of alkylphenol polyethoxylates entering UK estuaries. Mar. Pollut. Bull., 38: 109-18

Busan Metropolitan City. 2003 Fundamental Planning Report for River Improvement Works. Pusan, Korea. p. 265

Busan Development Institute. 2005 A study on the ecological and economic valuation and preservation plan for the estuary of Nakdong River. Pusan, Korea. p. 125

Busan Development Institute. 2006 Ecosystem monitoring in the estuary of Nakdong River. Pusan, Korea. p. 310

Choi, S. K. 2010 A Study on Analysis of Water Quality Trend for Downstreams in Nakdong River. M.S. thesis, Dept. Environ. Eng., Kyungpook Nat. Univ., Daegu, Korea

Colborn, T., F. S. Vom Saal. and A. M. Soto. 1993 Developmental Effects of Endocrine-Disrupting Chemicals in Wildlife and Humans. Environ. Health. Perspect., 101: 378-384

Ferguson, P. L., C. R. Iden and B. J. Brownawell. 2000 Analysis of Alkylphenol Ethoxylate Metabolites in the Aquatic Environment Using Liquid Chromatography-Electrospray Mass Spectrometry. Anal. Chem., 72(18): 4322-4330

Ferrara, F., F. Fabietti, M. Delise, A. P. Bocca and E. Funari. 2001 Alkylphenolic compounds in edible molluscs of the Adriatic sea (Italy). Environ. Sci. Technol., 35: 3109-3112

Fries, E and W. Puttmann., 2003., Occurrence and behaviour of 4-nonylphenol in river water of Germany. J. Environ. Monit., 5: 598-603

Giger, W., P. H. Brunner and C. Schaffner., 1984 4-Nonylphenol in sewage sludge: accumulation of toxic metabolites from nonionic surfactants. Science, 225: 623-625

Ham, Y. K., S. J. Oh and S. W. Kim. 2004 Monitoring of Bisphenol A and Nonylphenol in Waterworks System of Seoul, Korea. Anal. Sci. and tech., 17(5): 423-433

Isobe, T., H. Nishiyama, A. Nakashima and H. Takada. 2001 Distribution and behavior of nonylphenol, octylphenol, and nonylphenol monoethoxylate in Tokyo metropolitan area: their association with aquatic particles and sedimentary distribution. Environ. Sci. Technol., 35: 1041-1049

Isobe, T. and H. Takada. 2004 Determination of degradation products of alkylphenol polyethoxylates in municipal waste waters and rivers in Tokyo, Japan. Environ. Toxicol. Chem., 23(3): 599-605

Jobling, S., D. Sheahan, J.A. Osborne, P. Matthiessen and J.P. Sumpter. 1996 Inhibition of testicular growth in rainbow trout (Oncorhynchus mykiss) exposed to estrogenic alkylphenolic chemicals. Environ. Toxicol. Chem., 15: 194-202

Jonkers, N., T. P. Knepper and P. D. Voogt. 2001 Aerobic biodegradation studies of nonylphenol ethoxylates in river water using liquid chromatographyelectrospray tandemmass spectrometry. Environ. Sci. Technol., 35: 335-340

Kang, I. J., H. Yokota, Y. Oshima, Y. Tsuruda, T. Hano, M. Maeda, N. Imada, H. Tadokoro, T. Honjo. 2003 Effects of 4-nonylphenol on reproduction of Japanese medaka, Oryizias latipes. Environ. Toxicol. Chem., 22(10): 2438-2445

Kavlock, R. J., D. P. Daston, C. DeRosa, P. Fenner-Crisp, L. E. Gray,
S. Kaattari et al. 1996 Research Needs for the Risk Assessment of Health and Environmental Effects of Endocrine Disruptors: A Report of the U.S. EPA-sponsored Workshop. Environ. Health. Perspect., 104(4): 1-26

Kiceniuk, J. W. and S. Ray. 1994 Analysis of contaminants in edible aquatic resources. VCH Publishers, p. 551

Kim, K. H. 2005 Hydraulic characteristics and behavior of pollutants in Nakdong river estuary. M. S. thesis, Dept. Ocean Eng. Pukyong Nat. Univ., Pusan, Korea. p. 90

KORDI. 2004 Effect of endocrine disrupting compounds on coastal ecosystem. MEST, p. 183

Lee, S. H., S. H. Lee and C. H. Lee. 2005 Sources of Alkylphenol Polyethoxylate and their fate in the central Nakdong river basin. Korean J. Environ. Eng., 27(12): 1277-1284

Li, D. H., M. Kim, W. J. Shim, U. H. Yim, J. R. Oh and Y. J. Kwon. 2004a Seasonal flux of nonylphenol in Han River, Korea. Chemosphere, $\mathbf{5 6}$ : $1-6$

Li, D. H., M. Kim, W. J. Shim, U. H. Yim, S. H. Hong and J. R. Oh. 2004b Distribution of Nonylphenol in Gwangyang bay and the surrounding streams. Korean J. Environ. Biol., 22: 71-77

MEV and NIER. 2000 Report of research projects of endocrine disrupting chemicals. p. 897

NIER. 2006 Environmental monitoring of endocrine disrupting chemicals. MEV, p. 104

NIER. 2007 8th report of research projects of endocrine disrupting chemicals. MEV, p. 31

Park, M. S. 1997 A study on the water quality characteristics of the Suyeong river. M. S. Thesis, Major in Chem. Educ., Korea Nat. Univ. of Educ., Chung-Buk, Korea

Renner R. 1997 European bans on surfactant trigger transatlantic debate. Environ Sci Technol., 31: 316A-320A

Rice, C. P., I. Schmitz-Afonso, J. E. Loyo-Rosales, E. Link, R. Thoma, L. Fay et al. 2003 Alkylphenol and alkylphenol-ethoxylates in carp, water, and sediment from the Cuyahoga River, Ohio. Environ. Sci. Technol., 37: 3747-3754

Shang, D. Y., R. W. Macdonald and M, G. Ikonomou. 1999 Persistence of nonylphenol ethoxylate surfactants and their primary degradation products in sediments from near a municipal outfall in the strait of Georgia, British Columbia, Canada Environ Sci. Technol, 33: 1366-1372

Snyder, S. A., T. L. Keith, D. A. Verbrugge, E. M. Snyder, T. S. Gross, K. Kannan and J.P. Giesy. 1999 Analytical methods for detection of selected estrogenic compounds in aqueous mixtures. Environ. Sci. Technol., 33: 2814-20

Soto, A. M., H. Justicia, J. W. Wray and C. Sonnenschein. 1991 P-Nonylphenol: an estrogenic xenobiotic released from "modified" polystyrene. Environ Health Perspect., 92: 167-173

Tsuda, T, A. Takino, M. Kojima, H. Harada, K. Muraki and M. Tsuji. 2000 4-Nonylphenols and 4-tert-octylphenol in water and fish from rivers flowing into Lake Biwa. Chemosphere, 41 $757-62$

Wu, Z. B., Z. Zhang, S. P. Chen, F. He, G. P. Fu and W Liang. 2007 Nonylphenol and octylphenol in urban eutrophic lakes of the subtropical China. Fresen. Environ. Bull., 16: 227-234 